${ }^{2}$ Hamby, R I, Zungraich, S, and Sherman, L, fournal of the American Medical Association, 1974, 229, 1744.

${ }^{3}$ Rubler, S, et al, American fournal of Cardiology, 1972, 30, 595.

4 Gibson, D G, and Brown, D J, British Heart Fournal, 1973, 35, 1141.

5 Upton, M T, Gibson, D J, and Brown, D J, British Heart fournal, 1976, 38, 1001 .

6 Sanderson, J E, et al, British Heart fournal, 1977, 39, 661.

7 Sanderson, J E, et al, British Heart fournal. In press.

${ }^{8}$ Wheeler, T, and Watkins, P J, British Medical fournal, 1973, 4, 584.
${ }^{9}$ Gibson, D G, Prewitt, T A, and Brown, D J, British Heart Fournal, 1976, 38, 1010.

${ }^{10}$ Ruttley, M S, et al, Circulation, 1974, 50, 306.

11 Straub, H, Fournal of Physiology, 1910, 40, 378.

12 Rubinstein, J J, Pohost, G M, and Foster, J R, Clinical Research, 1973, 21, 446 .

(Accepted 28 November 1977)

\title{
SIDE EFFECTS OF DRUGS
}

\section{Levamisole-induced vasculitis due to circulating immune complexes}

The immunostimulant drug levamisole is being assessed in the treatment of many conditions, including rheumatoid arthritis. ${ }^{1}$ Reports of side effects are accumulating, especially in patients with immunological disorders. In one group of 69 patients with cancer receiving immunotherapy with levamisole, three developed non-

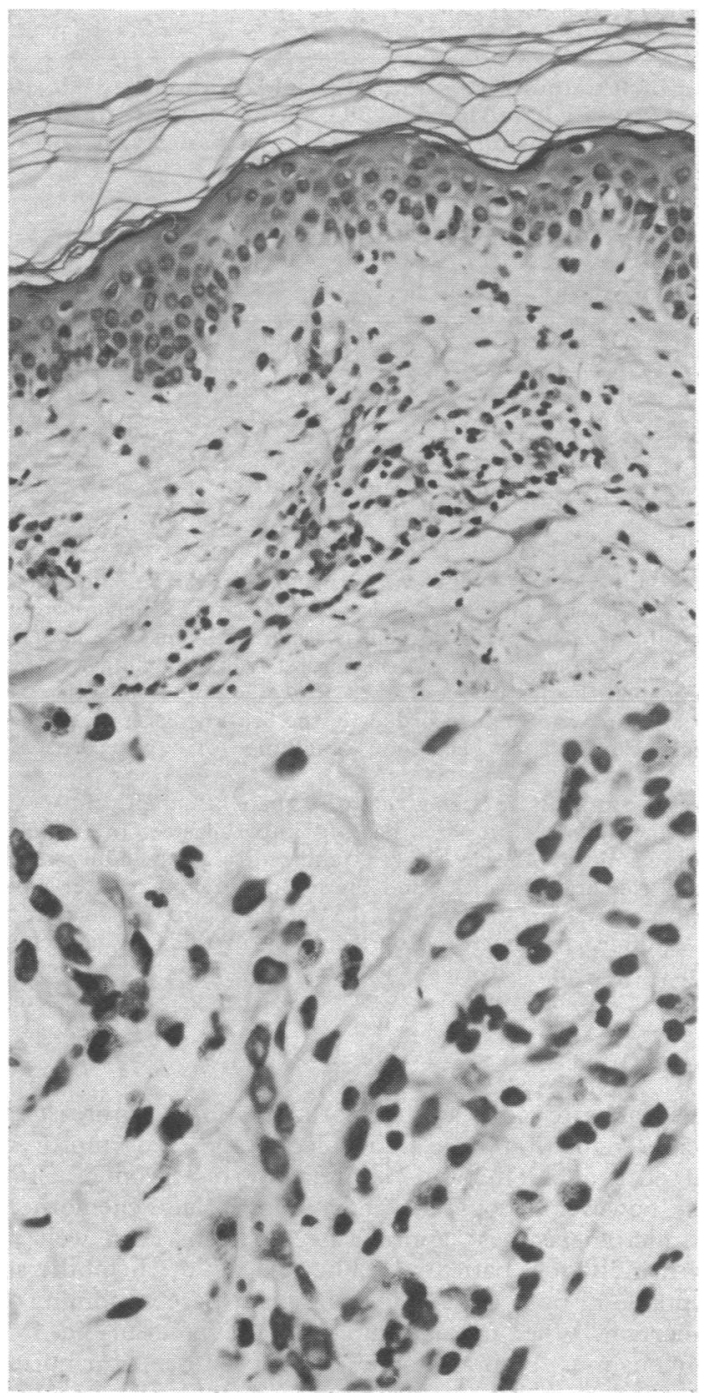

Biopsy specimen of forearm skin. Above: Low-power view showing leucocytoclastic vasculitis with inflammatory cells and nuclear debris around small cutaneous vessels. (Haematoxylin and eosin. $\times 500$.) Below: Highpower view showing prominent eosinophils. ( $H$ and $\mathrm{E} . \times 1250$.) specific rashes. ${ }^{2}$ We describe a patient who developed a cutaneous leucocytoclastic vasculitis while receiving levamisole for rheumatoid arthritis, a hitherto unrecognised complication.

\section{Case report}

A 65-year-old woman with seropositive rheumatoid arthritis of 10 years' duration began treatment with $150 \mathrm{mg}$ levamisole daily. She was also taking enteric-coated aspirin (Nu-seals) and occasional Distalgesic tablets (dextropropoxyphene hydrochloride and paracetamol). Two months later, while continuing on this dose of levamisole, she developed a widespread rash with a livedo pattern, chiefly on the arms and legs; she was otherwise well and thought that the arthritis had improved. Biopsy of a typical lesion on the forearm showed a leucocytoclastic vasculitis with predominant eosinophils (see figure).

Immunofluorescence showed IgM in the basement membrane and C3 around the vessels. The haemoglobin was $11.8 \mathrm{~g} / \mathrm{dl}$; white cell count was $7 \cdot 0 \times 10^{9} / 1\left(7000 / \mathrm{mm}^{3}\right)$; platelets were plentiful; and ESR was $27 \mathrm{~mm}$ in the first hour. Serum complement concentrations $\left(\mathrm{CH}_{50}, \mathrm{C} 3\right.$, and $\left.\mathrm{C} 4\right)$ were normal. Circulating immune complexes were not detected by measuring anticomplement activity or by the platelet aggregation test. Nevertheless, a histamine skin-weal test ${ }^{3}$ reproduced the leucocytoclastic vasculitis in clinically unaffected site. Biopsy of control, uninjected skin showed increased numbers of eosinophils around the vessels but no vasculitis. Immunofluorescence of the histamine-injected site showed IgM and complement, as in the clinically affected skin, but these were absent in the control specimen. The rash rapidly disappeared when levamisole was withdrawn. One month later the histamine skin test was repeated. The uninjected skin was normal, but the injected site showed infiltration of round cells, with immunoglobulins and complement around the vessels.

\section{Comment}

Levamisole was apparently responsible for the vasculitic rash since the condition rapidly disappeared on withdrawal of the drug, though the other treatment was unchanged. Immunological mechanisms were clearly important. Although serological tests for circulating immune complexes gave negative results, the histamine skin test produced a reaction. This was possibly because histamine allowed sufficient immune complexes to accumulate in one site to trigger complementmediated damage and thus reproduce the vasculitis.

Levamisole-induced agranulocytosis has also been shown to be due to immunological mechanisms by the finding of leucocytotoxic agglutinins. ${ }^{4}$ Arthritis induced by levamisole has been reported in Crohn's disease ${ }^{5}$ with negative serological tests for immune complexes. As in Crohn's disease, our patient developed a well-recognised complication of the primary disease while on levamisole. Clearly doctors cannot dismiss the appearance of a complication as being due to the disease alone in patients receiving levamisole unless it persists after withdrawal of the drug. Our patient's abnormal response to the histamine test one month after stopping treatment suggests that immune complexes were persisting, but not in sufficient quantity to cause a clinical vasculitis. This supports the possibility that levamisole produces complications by unmasking pre-existing but latent immunological abnormalities rather than initiating disease. Further reports of side effects of levamisole will shed more light on both the mode of action of the drug and the diseases it is used to treat.

We thank Dr St John Dixon for permission to report this case and Dr Pat Burton for the histological report.

1 Huskisson, E C, et al, Lancet, 1976, 1, 393.

2 Parkinson, D R, et al, Lancet, 1977, 2, 1129. 
${ }^{3}$ Baverman, I M, and Yen, A, fournal of Investigative Dermatology, 1975, 64, 105.

4 Rosenthal, M, et al, Lancet, 1976, 1, 369.

5 Segal, A W, et al, British Medical fournal, 1977, 2, 255.

(Accepted 23 November 1977)

Southmead Hospital, Bristol BS10 5NB

DIANA G MACFARLANE, MB, MRCP, medical registrar

Royal National Hospital for Rheumatic Diseases, Bath BA1 1RL PAUL A BACON, MB, MRCP, consultant rheumatologist

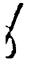

\section{Cutaneous necrotising vasculitis induced by levamisole}

The anthelmintic agent levamisole has immunostimulant properties in patients with defective cell-mediated immune responses. We are assessing the drug in patients with breast cancer to see whether it can maintain surgically induced remission. One such patient developed a severe cutaneous necrotising vasculitis, which disappeared once the drug was withdrawn.

\section{Case report}

A 59-year-old woman had been receiving thrice-weekly levamisole 150 mg/day for three months, when in May 1975 she developed fever and a severe rash. Cutaneous necrotising vasculitis was diagnosed. Biopsy of one of the lesions showed intense neutrophil and eosinophil infiltration of the vessel wall with obliteration of the lumen. There were no other physical abnormalities, and no sign of the original disease was noted. She had not been taking any other drugs.

Haemoglobin was $13 \mathrm{~g} / \mathrm{dl}$ and white cell count $3.0 \times 10^{9} / 1\left(3000 / \mathrm{mm}^{3} ; 30 \%\right.$ segmented neutrophils, $8 \%$ eosinophils, $10 \%$ monocytes, $52 \%$ lymphocytes). Results of complement studies were within normal limits, and other immunological and biochemical values were normal. A bone-marrow aspirate showed a normal distribution of white and red cells but a moderate increase in eosinophils. A chest radiograph was normal.

Levamisole was discontinued and the patient given a short course of prednisone $40 \mathrm{mg}$ daily. After two weeks the clinical picture returned to normal, and three months later the skin lesions showed no signs of recurrence and the white cell count was normal.

\section{Comment}

Levamisole-induced vasculitis has not been reported, despite wide use of the drug in various conditions, including malignant and rheumatic diseases. ${ }^{1-3}$ The pathogenesis of our patient's skin reaction is unknown, though histologically it was similar to an Arthus-type reaction, in which immune-complex formation or complement activation is usually implicated. We found no complement abnormalities in our patient, but the tests did not exclude a local type III reaction.

The peripheral blood neutropenia in our patient also implicates levamisole as the causal agent, since neutropenia and agranulocytosis are associated with levamisole treatment. ${ }^{3}$ The exact mechanism of this reaction is unknown, but the peripheral and central eosinophilia suggest a hypersensitivity reaction. Although we did not challenge the patient (for ethical reasons) we think that levamisole was the likely cause of the vasculitis.

\footnotetext{
1 Sampson, D, and Lui, A, Cancer Research, 1976, 36, 952.

2 Schuermans, Y, Lancet, 1975, 1, 111.
}

${ }^{3}$ Scheinberg, M A, et al, Arthritis and Rheumatism. In press.

(Accepted 29 November 1977)

Division of Rheumatology and Clinical Immunology, Hospital Ana Costa, Rua Pedro Américo 50, Santos Estado de Sáo Paulo, Centro de Estudos do Hospital Sirio Li banes and Disciplina de Imunologia, Escola Paulista de Medicina, Brazil

MORTON A SCHEINBERG, RD, PHD

JOAOO BATISPA GOMES BEZERRA, MD

FERNADHO A ALMEIDA, MD

LINNEU A SILVEIRA, MD

\section{SHORT REPORTS}

\section{Toxicity of oral adjuvant chemotherapy in breast cancer}

The results of management of "early" breast cancer will be improved only by systemic treatment, since the disease should be regarded as systemic in many patients at the time of initial treatment. ${ }^{1}$ We report the preliminary results of a trial of oral adjuvant chemotherapy with two drugs in 202 patients over 18 months. The aims of the study were, firstly, to observe the incidence and degree of toxicity, which must be acceptable to patients and clinicians; and, secondly, to establish the ease of administration-that is, the treatment should be within the capability of any hospital in Britain.

\section{Trial design and results}

The regimen is on trial in 70 centres in the UK and Ireland. Women are treated as outpatients in either surgical or chemotherapy clinics. Primary treatment is at the discretion of the surgeon, who has the option of either simple mastectomy and "watch" policy or simple mastectomy and radiotherapy or radical mastectomy. Patients under 70 with histologically evident spread to lymph nodes and in stage I or II are randomly allocated to chemotherapy or no chemotherapy.

Two oral drugs were chosen to try to maximise acceptability to patients and clinicians while retaining the advantages of multiple-drug treatment. ${ }^{23}$ Melphalan $10 \mathrm{mg}$ is given on five consecutive days together with methotrexate $15 \mathrm{mg}$ on the first day. This is repeated every six weeks for two years and should be started within four weeks after surgery. Patients under $50 \mathrm{~kg}$ receive melphalan $7.5 \mathrm{mg}$ and methotrexate $10 \mathrm{mg}$. Should marrow depression occur (white cell count (WBC) $<4 \times 10^{9} / 1$; platelets $<100 \times 10^{9} / 1$ ) the dosages are halved. A course is omitted when the WBC falls below
$2.5 \times 10^{9} / 1$ and platelets below $75 \times 10^{9} / 1$ or if liver function deteriorates. Methotrexate is withheld if oral ulceration occurs. When marrow or liver function returns to normal treatment is restarted. Nausea and vomiting may be controlled with antiemetics at the discretion of the clinician in charge.

The end-point is disease recurrence or death. Full clinical details at times of entry and follow-up are recorded by the central secretariat for computer processing. Emphasis is placed on obtaining toxicity records after each course.

So far 484 courses have been given to 102 patients; their primary treatment was as follows (controls in parentheses): simple mastectomy 43 (57), simple mastectomy and radiotherapy 17 (13), and radical mastectomy 42 (32). Two patients refused oral treatment, and one stopped treatment after experiencing nausea with one tablet. In $68(14 \%)$ the dosage had to be halved temporarily because of transient toxicity (table), usually in the first few courses. No patient needed a wig.

\section{Comment}

Three years after adjuvant chemotherapy for early breast cancer an appreciable reduction in distant metastases ${ }^{2}$ and improvement in survival $^{3}$ occur, predominantly in premenopausal women. Uncertainty remains, however, about the most appropriate chemotherapy for distant micrometastases; appropriate regimens may well prove to vary with individual patients. ${ }^{23}$ The toxicity of chemotherapy must be acceptable to both patient and clinician. Ease of administration is also important. When considering the facilities available in the UK the regimens must be practicable. The 70 centres contributing to the study confirm that this two-drug regimen fulfils these requirements.

The therapeutic efficacy of adjuvant chemotherapy must await results at three, five, and ten years after initial treatment. Melphalan alone results in improvement at three years ${ }^{2}$ and is less toxic than more powerful multiple-drug regimens. ${ }^{3}$ The preliminary results on 